\title{
Actuaciones sobre el patrimonio arquitectónico de Málaga para su conversión en espacios expositivos
}

\section{Antonio Jesús Santana Guzmán ${ }^{a}$}

${ }^{a}$ Departamento de Historia del Arte, Universidad de Málaga, Facultad de Filosofía y Letras, Campus de Teatinos, 29071 Málaga. asantana@uma.es

\begin{abstract}
Resumen
El buen clima de Málaga ha provocado que durante mucho tiempo sea un destino turístico anhelado como lugar de reposo y disfrute del mar. A mediados del siglo XX, el territorio de la Costa del Sol se explotó y transformó completamente su paisaje concibiendo una oferta casi fundamentada en su buen litoral. En ese momento, poco destacaban los espacios culturales, no planificándose la creación de nuevas entidades destinadas a tal fin hasta comienzos del siglo XXI. Posteriormente se apostó por la candidatura a Capital Europea de la Cultura 2016, tras no ser elegida, se viró su futuro hacia la marca "Málaga, ciudad de museos". Para la ubicación de estas colecciones fue necesaria la adaptación de edificios históricos a nuevos usos. Estas intervenciones tuvieron sus luces y sus sombras en la conservación y recuperación del patrimonio. A través del estudio y análisis de dichas acciones y de la bibliografia generada, se pretende poner en valor las actuaciones positivas que han sacado a la luz y/o han aportado nuevos valores al patrimonio de esta ciudad.
\end{abstract}

Palabras clave: cultura, patrimonio, museos, conservación, rehabilitación, Málaga.

\begin{abstract}
The good climate of Malaga has made it a long-awaited tourist destination for taking a rest and enjoying the sea. Especially in the middle of the 20th century, the Costa del Sol area was exploited, constructing accommodations that completely transformed the landscape of the city. These modifications promoted the conception of an offer based mostly on its attractive coastline. At that time, the cultural spaces offered by the city were hardly highlighted, so the creation of new entities for this purpose was not planned until the beginning of the 21st century. Afterwards, Malaga was included as a candidate to become a European Capital of Culture in 2016. Even though it was not chosen, the city still turned its future towards the brand "Malaga, city of museums". In order to achieve this objective, it was necessary to adapt historical buildings for new purposes. Such interventions had their lights and shadows in the conservation and recovery of the heritage of the city. Through the study and analysis of these actions and the bibliography generated, it is intended to value the positive actions that have brought to light and / or have contributed new values to the heritage of this city.
\end{abstract}

Keywords: culture, heritage, museums, conservation, restoration, Malaga. 


\section{Introducción}

La elección de un destino por parte del turista dependerá principalmente de la oferta que aquél ofrezca. Desde finales del siglo XX y principios del actual, muchos territorios, que antes promocionaban otras cualidades, se han volcado por completo en el turismo cultural. Esta situación obliga al emplazamiento de espacios expositivos, preferentemente, en los centros históricos para que, así, automáticamente queden incluidos en los itinerarios turísticos principales, lo que deriva en la búsqueda de ubicaciones idóneas en el entramado urbano existente. Para acoger tales funciones resulta necesario un continente que pueda custodiar, de manera apropiada, el contenido cultural planteado. Para ello existen varias opciones: la elección de un edificio histórico, que además añada valor a la colección, convirtiéndose así en uno de los principales reclamos de la misma; optar por la construcción ex profeso de un inmueble que se adapte por completo a las necesidades específicas de estas dotaciones, e intentando insertar una arquitectura que también sirva de elemento propagandístico de la nueva entidad; o en la combinación de ambas propuestas.

En el caso de Málaga, la mayoría de las dotaciones culturales se ubican en el denominado casco antiguo y su entorno más cercano. Como en muchas otras localidades, gran parte de este caserío se encontraba en un estado de conservación lamentable. Esta situación fomentó la propuesta de recuperar algunos de los edificios que lo conformaban, transformándolos en museos y espacios expositivos. Han sido muchas las intervenciones que se han realizado en esta ciudad y por tanto diversos los grados en el respeto por el patrimonio arquitectónico preexistente a la hora del cambio de uso, viéndose principalmente afectado por las condiciones en las que se encontraba el continente; las exigencias de la colección y su propietario; el interés por la conservación; y otros aspectos afines.

A continuación, se presenta una breve síntesis de las principales actuaciones llevadas a cabo. El objetivo principal de este texto es poner en valor las acciones positivas que han sacado a la luz elementos patrimoniales desconocidos, ocultos en ocasiones en el subsuelo y otras por operaciones desafortunadas o simplemente funcionales de otros tiempos. Este estudio hace uso de una metodología sustentada en una búsqueda bibliográfica exhaustiva, relativa a las interveciones llevadas a cabo y a los documentos internacionales que velan por la protección del patrimonio; en la visita, a lo largo de un amplio recorrido cronológico, de los edificios incluidos; y en los conocimientos adquiridos a lo largo de los años trabajados sobre el patrimonio de esta ciudad.

\section{Málaga, destino turístico}

\subsection{Oferta de sol y playa}

Una de las cualidades más destacables de Málaga es su buen clima, lo que ha hecho que, desde siglos atrás, la ciudad se haya situado como destino recomendado para la sanación, el reposo y los baños. Del desarrollo de estas actividades a lo largo del siglo XIX y principios del XX, quedan testimonios a través de planos y fotografías de la época en los que se indican los establecimientos más importantes y se recogen imágenes de los mismos. Pero, actualmente, apenas quedan vestigios de este periodo. Se mantienen los Baños del Carmen, aunque en un estado lamentable y en espera de una polémica intervención que causaría graves daños tanto al conjunto como al entorno medioambiental del frente marítimo en el que se emplaza.

En las primeras décadas de la centuria pasada comenzaron a instalarse los primeros alojamientos y hoteles en la Costa del Sol. En principio, en un número mucho más reducido siendo construcciones más integradas en el paisaje que, a partir de mediados de siglo, comenzaron a convertirse en altos prismas verticales. A esta tipología se le sumaron otras como la de los apartahoteles o incluso las segundas residencias. A pesar de que muchos de estos elementos son dignos de destacar entre las mejores piezas de la arquitectura contemporánea nacional, el problema se planteó cuando se comenzó a ocupar y saturar por completo el litoral, transformando para siempre el territorio y su skyline.

\subsection{La Cultura en el siglo $\mathrm{XX}$}

En 1916 se creó el Museo Provincial de Bellas Artes, entidad que abrió al público en un vivienda propiedad del marqués de Larios, en la calle Pedro de Toledo -demolida- y posteriormente se instaló en la sede de la Academia de 
Bellas Artes de San Telmo - actualmente es el Ateneo-, en la plaza principal de la ciudad. En 1961 fue traslado a uno de los edificios residenciales más imponentes de la ciudad, el denominado como Palacio de los condes de Buenavista, nomenclatura que se manteniene en la tradición y en la historiografía local, si bien se creó como Casa Cazalla, noble que la mandó construir (Giménez, 2004, p. 53). Dicho inmueble sufrió una serie de reformas a partir de 1947, entre ellas la demolición de espacios considerados menos nobles, ubicados en la zona trasera, y la reconstrucción de un patio neomudéjar ideal a partir de restos de arquerías que aparecieron durante las obras (Romero, 1989, pp. 11 y 14).

Por otro lado, el Museo Provincial Arqueológico se instaló en 1947 en uno de los conjuntos históricos más importantes de la capital, la Alcazaba (Martínez, 2013, p. 39). La elección estuvo relacionada con sus fondos, pues parte de los mismos se conformaron con los hallazgos realizados en dicho recinto durante las obras de recuperación del monumento en las primeras décadas del siglo XX ya que, con el paso de los años, éste se había transformado en un barrio popular.

Cabe destacar la creación, en 1961, de otro espacio expositivo, en este caso de gestión privada, el Museo de Artes y Costumbres Populares, administrado por una caja de ahorros y ubicado en el inmueble de la Sociedad Económica de Amigos del País. Poco después, en 1976 se trasladó a su actual sede, el Parador o Mesón de la Victoria, recuperándose así un edificio del siglo XVII abandonado y en estado de ruina (MUACPMÁLAGA, s. f.), tratándose de uno de los escasos ejemplos arquitectónicos de ese periodo que se conserva en la localidad.

\subsection{EI nacimiento de nuevos espacios museísticos}

Esa era la oferta cultural que la ciudad de Málaga ofrecía a sus visitantes, y ciudadanos, a partir de mediados del siglo $\mathrm{XX}$, no siendo uno de los reclamos principales para conocer este territorio. Sin embargo, a finales de dicha centuria comenzó a planificarse la creación de nuevos espacios culturales.

Uno de los más destacados, no sólo por su función expositiva, sino también por su papel como centro de investigación, se dedicó a uno de sus habitantes más universales. Así, en 1988, se estableció el Museo Casa Natal de Picasso, que, ubicado en origen en la primera planta del inmueble, pasó, en 1998, a ampliarse ocupando la totalidad de éste (Fundación Picasso, s. f.). Destinado desde su construcción a uso residencial, se rehabilitó su fachada y se reordenó el espacio interior del mismo para dar cabida a nuevas funciones, manteniendo algunos elementos originales como es el caso de la crujía principal y el cuerpo de escaleras.

En las postrimerías del siglo se realizó un nuevo edificio destinado a acoger diversas exposiciones temporales. Dicho inmueble se reconvirtió, algunos años después, en el Museo del Patrimonio Municipal (MUPAM), el cual fue ampliado en 2003 (Ayuntamiento de Málaga, s. f.) tras la demolición de la Coracha, un barrio que se había convertido en referente icónico de la Málaga popular. Sólo dos de esas viviendas fueron salvadas, gracias a la lucha personal de sus propietarios, siendo esta acción posteriormente premiada por el propio Consistorio.

Uno de los edificios que recuperó la ciudad para uso cultural fue el antiguo Mercado de Mayoristas. En 1999 se comenzó su rehabilitación para acoger el Centro de Arte Contemporáneo (CAC). El estado de conservación del inmueble era muy deficiente, pues había sido declarado en ruina, lo que conllevó su clausura como espacio de venta al por mayor en 1981 (Coloma et al., 2003, p. 586). La propuesta recuperó elementos originales a partir de los restos conservados, lo que puso en valor las formas del edificio original. Si bien, poco antes de su inauguración en febrero de 2003, se decidió transformar radicalmente su aspecto, tanto interior como exterior, donde la sustitución del color almagra por el blanco fue el cambio más significativo (Fig. 1).

En 1997 el, ya citado, Palacio de los condes de Buenavista, que hasta entonces acogía la sección de Bellas Artes del Museo Provincial, fue elegido para la instalación en él del Museo Picasso Málaga, que fue inaugurado en octubre de 2003. A pesar de mantener el mismo uso, el inmueble volvió a ser readaptado para adecuarse a las necesidades expositivas del momento. En esta intervención, el criterio persiguió recuperar los elementos originales de esta residencia nobiliaria y se decidió eliminar los añadidos del siglo XX (Giménez, 2004, p. 111). Entre las modificaciones cabría citar la modificación de algunas de las circulaciones y también el desafortunado incendio que destruyó una de las armaduras de madera de la planta superior (Peláez, 2020/03/09). Asimismo, el conjunto se vio ampliado con una serie de viviendas que se mantenían en la antigua judería de la ciudad, y de las cuales tan sólo se conservaron algunas 
fachadas y el trazado urbano; en esta parte se utilizó una arquitectura contemporánea (Fig. 2). Las obras del inmueble permitieron sacar a relucir los restos arqueológicos conservados en el subsuelo, de gran valor histórico por localizarse en el sector más antiguo de la ciudad (García, 2016, pp. 848-855), que se insertaron en el recorrido expositivo al convertirlos en visitables. En 2006 esta actuación fue premiada con el Institute Honor Awards for Architecture (Museo Picasso Málaga, s. f.).

En 2008 se inauguró el Museo del Vino de Málaga. Como sede del mismo se eligió un edificio señorial dieciochesco, el Palacio de Biedmas. Pero en este caso, tan sólo se restauró la fachada principal del mismo, que se mantuvo como mero decorado, pues el resto fue demolido por completo y construido como nueva obra.

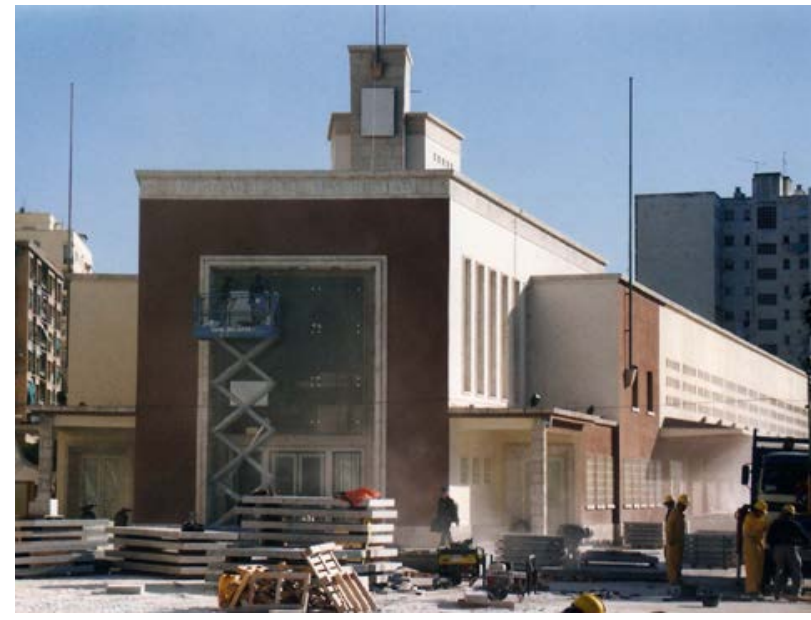

Fig. 1 CAC, cambio de color y otras modificaciones

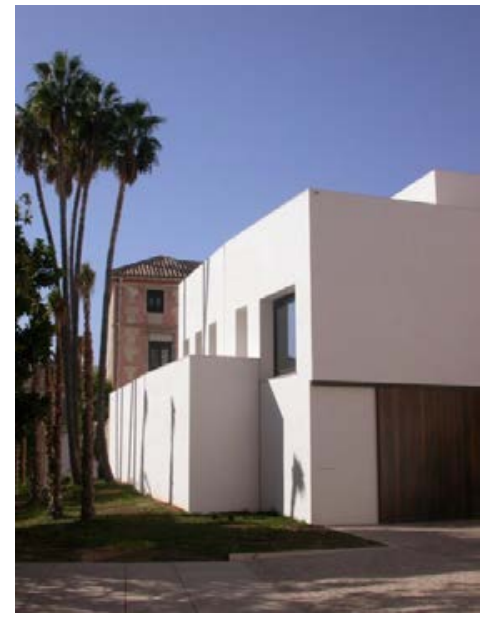

Fuentes: Santana, A (2003) y G. Aranda, S (s. f.)

Fig. 2 Museo Picasso, volúmenes contemporáneos y fachadas conservadas

Un año después, en 2009, tuvo lugar la apertura de la Colección del Vidrio y Cristal de Málaga, que se ubicó también en un edificio del siglo XVIII. Su gestión es privada, y la restauración del inmueble ha consistido en una recuperación meticulosa, con la reconstrucción de zonas bastante deterioradas, y el descubrimiento de antiguas pinturas murales en su fachada (Fig. 3). El programa iconográfico no está completo ya que parte del conjunto original fue adquirido por otro propietario y derribado (Heredia, 2010, p. 46). Actualmente existe una propuesta para la futura ampliación de este espacio cultural, que si bien será de nueva construcción, se inspirará en la arquitectura dieciochesca y no agota al máximo la volumetría edificable de su solar, pretendiendo así recuperar el espíritu del barrio en el que se emplaza, además de hacer visitables los restos arqueológicos alfareros conservados en su solar (Colección del Vidrio y Cristal de Málaga, s. f.).

En 2011 se instala en la ciudad el Museo Carmen Thyssen Málaga, eligiéndose para su sede un céntrico inmueble, el Palacio de Villalón, en el que ya se pensó ubicar otros usos culturales, como el Museo de la Ciudad o el Museo Interactivo de la Música. A mediados del siglo XX esta casa palaciega fue completamente transformada con un lenguaje contemporáneo mientras funcionaba como establecimiento comercial, clausurando su patio y alterando considerablemente la fachada principal. Ambos elementos fueron recuperados junto a otros vestigios, entre ellos sus magníficas armaduras, que se conservaban ocultas, sacando así a la luz las distintas fases de construcción de esta magnífica residencia. Desafortunadamente, durante la realización de las obras, fueron sustraídas algunas piezas arquitectónicas de gran valor como el ajimez de la escalera principal. El resto de inmuebles que se anexaron al conjunto fueron demolidos -o drásticamente transformados sus interiores- y sustituidos por volúmenes contemporáneos que no en todos los casos dialogan acertadamente con su entorno y en los que se han insertado algunos restos de pinturas murales preexistentes (Camacho, 2013, p. 247). Unas de las actuaciones más positiva fueron las excavaciones arqueológicas que sacaron a la luz, entre otros elementos, una interesante villa romana con un posible ninfeo (Fig. 4) (Museo Carmen Thyssen Málaga, s. f.), si bien aún no se han solucionado los problemas con los niveles freáticos que impiden su apertura al público. 


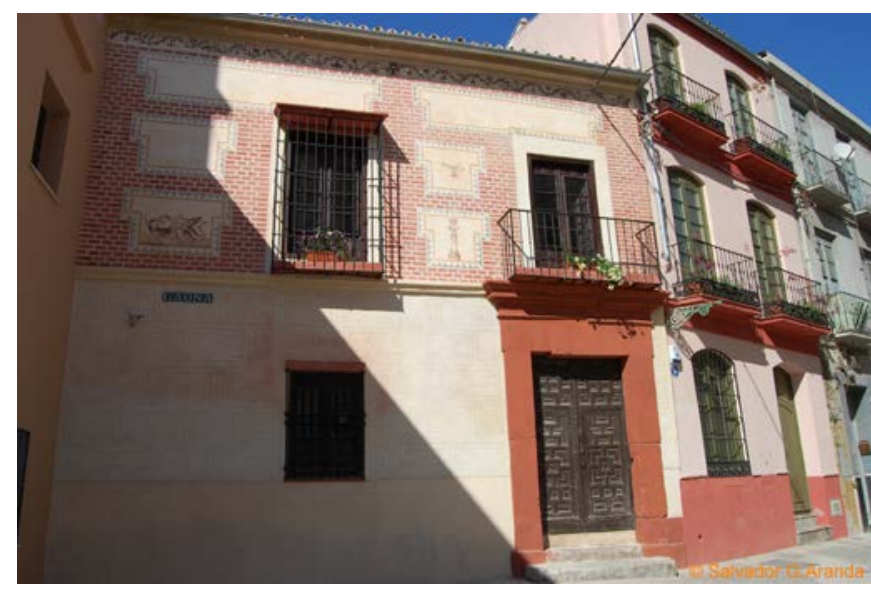

Fig. 3 Colección del Vidrio y Cristal, fachada

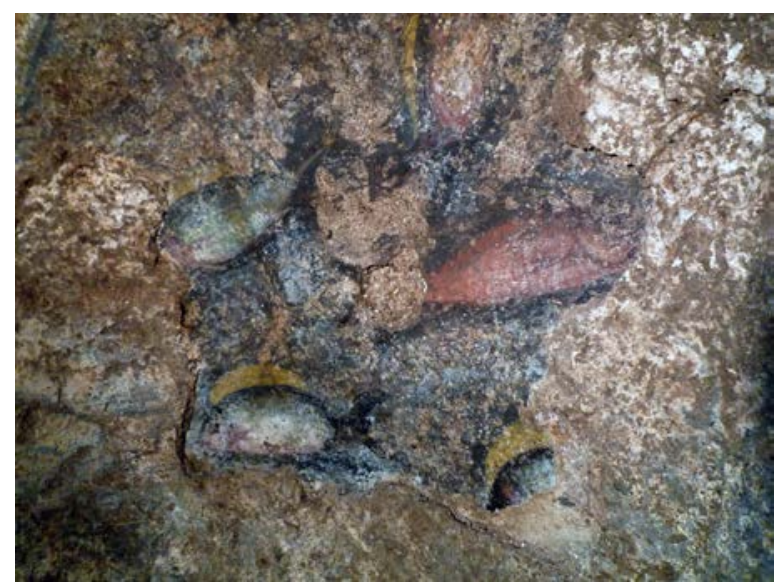

Fuentes: G. Aranda, S (2009) y Museo Carmen Thyssen Málaga (2010)

Fig. 4 Museo Carmen Thyssen, detalle de la decoración del posible ninfeo

La reapertura del Museo Interactivo de la Música Málaga (MIMMA) tuvo lugar en 2013. Como nueva sede se eligió el Palacio del Conde de las Navas, inmueble dieciochesco en un lamentable estado de conservación del que tan sólo se mantuvo su estructura y fachada principal, añadiéndosele además un nuevo volumen en el espacio del patio original (Piedrola, 2016, p. 57). Si bien, gracias a esta actuación el edificio quedó salvado de su completa demolición, cabe indicar que algunas de las intervenciones y la descontextualización de varios elementos originales han desvirtuado el espíritu señorial de este conjunto (Fig. 5). Es posible observar los restos arqueológicos localizados en su parcela.

En 2016 tuvo lugar la inauguración de uno de los espacios expositivos más importantes para este territorio, el Museo de Málaga, institución que desde 1972 se conforma por los antiguos museos provinciales de Bellas Artes y Arqueológico. Sus sedes fueron clausuradas en 1997 y 1996 respectivamente, por lo que el ciudadano estuvo privado de sus fondos durante veinte años. Para la ubicación del mismo y tras largas luchas por parte de la ciudadanía, se consiguió el Palacio de la Aduana, un inmueble administrativo construido entre los siglos XVIII y XIX que perdió su cubierta original, inclinada, en un pavoroso incendio en 1922. En el proyecto de rehabilitación como continente cultural se decidió devolverle su perfil original, aunque con una estética contemporánea, con el uso de grandes tejas metálicas (Fig. 6), material poco apropiado para un inmueble destinado a custodiar obras de arte y construido en esta latitud, tal y como quedó demostrado en 2019 tras la grave avería que sufrió el equipo de climatización (López, 2019/05/10). Las fachadas se rehabilitaron, se conservaron las bóvedas vaídas de la primera planta y de las escaleras principales. Es una intervención interesante donde destaca el lenguaje contemporáneo, si bien en algunos casos se han eliminado preceptos neoclásicos del inmueble original.

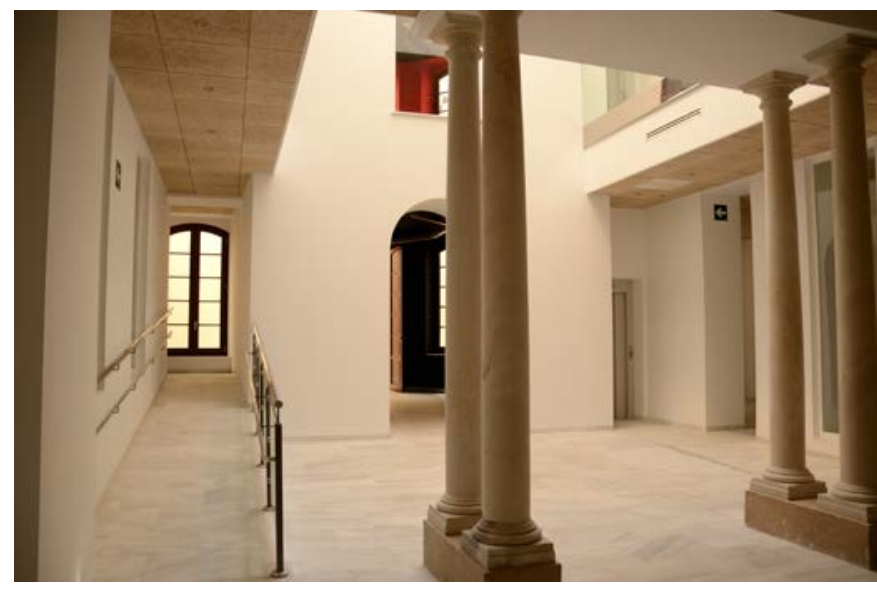

Fig. 5 MIMMA, interior

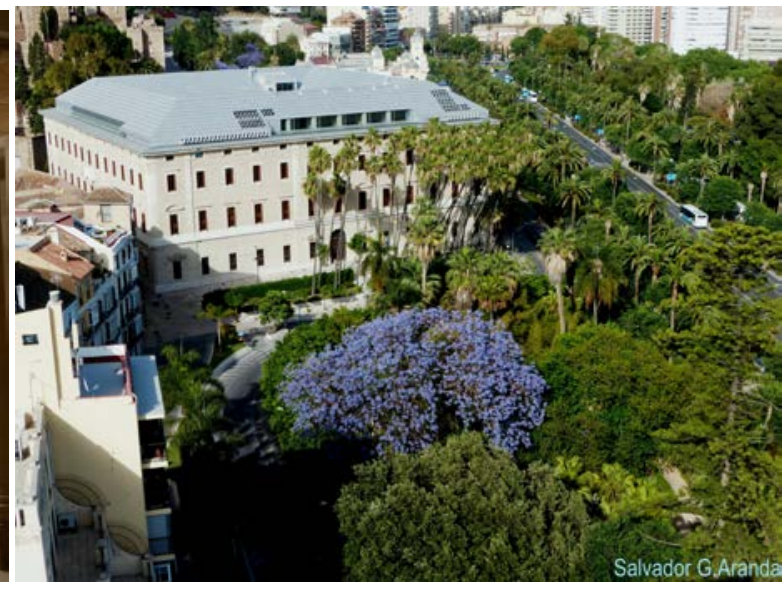

Fuentes: MIMMA (2012) y G. Aranda, S (2014)

Fig. 6 Museo de Málaga, vista aérea exterior 
Los ejemplos ya citados se ubican en el denominado Centro Histórico o en su entorno más cercano, si bien existen otros conjuntos ubicados a una distancia más considerada que, como aspecto positivo, han colaborado -aunque en un porcentaje muy reducido- a la descentralización cultural del casco antiguo.

Uno de ellos es la antigua Real Fábrica de Tabacos, conocida como Tabacalera, un amplio complejo industrial que fue clausurado en 2002. Varios fueron los proyectos culturales fallidos que se plantearon allí, hasta que en 2010 se inauguró, en parte de sus instalaciones, el Museo Automovilístico de Málaga (Sur, 2010/09/17). Para su adecuación se rehabilitaron varios pabellones y se insertó un elemento en clave contemporánea para marcar el punto de acceso. Posteriormente se recuperaron nuevos espacios con la apertura en 2015 de la denominada Colección del Museo Ruso de San Petersburgo (Colección del Museo Ruso, 2015/03/27). La restauración de este conjunto ha sido buena, si bien parte de su parcela se vendió para la construcción de edificios de viviendas que han colmatado un espacio que bien se podría haber permutado acogiendo un parque público que complementase esta oferta de ocio.

Otro es la antigua Casa de Misericordia, edificio construido a principios del siglo XX para uso piadoso. En él se instaló en 2013 La Térmica, un centro cultural dedicado al arte contemporáneo. La actuación sobre el mismo fue mínima, pues ya se intervino en la década de 1980 y mantenía un estado de conservación óptimo (La Térmica, s. f.). Tras su reconversión se puso en valor su original pavimento de baldosas hidráulicas que, incluso, se convirtió en símbolo de este espacio, si bien a comienzos del año 2020 se ha eliminado una parte del mismo para adecuar algunas zonas a la normativa vigente (Vázquez, 2020/01/16) perdiendo con ello parte de su valor original. Otros elementos nuevos a destacar son los parasoles instalados en los vanos del piso superior, que contrastan con la estructura original, pero que son completamente reversibles.

\section{Conclusiones}

Al tratar este apartado es muy importante tener en cuenta que el Centro Histórico de Málaga posee el máximo régimen de protección en la normativa española al tratarse de un Bien de Interés Cultural (BIC), cuyo expediente fue incoado en 1985 y dispuesto en 2012. Asimismo, hay que considerar que el Catálogo de Edificios Protegidos que abarca este sector, no se ha actualizado desde su realización a finales de la década de los ochenta, lo que influye negativamente en las intervenciones sobre los inmuebles que abarca.

Tal y como se ha destacado existen luces y sombras en la reconversión del casco antiguo de la ciudad en un amplio complejo museístico y expositivo. No se puede obviar que la creación de estos nuevos espacios ha recuperado ejemplos únicos de la historia de la ciudad que podrían haber sucumbido ante el paso del tiempo y haber desaparecido. Pero también es cierto que la puesta en valor de sus entornos, antes degradados y poco deseados -no sólo por los turistas, sino por los propios ciudadanos-, junto al evidente éxito conseguido con los planes estratégicos de la capital de la Costa del Sol (Silva y Fernández, 2017, pp. 91-93), han ocultado algunas intervenciones poco deseables y en las que se ha perdido para siempre parte del patrimonio arquitectónico de la ciudad en pro del espacio expositivo.

Es necesario alcanzar el equilibrio entre los bienes existentes y su adaptación para nuevo uso, sin perjudicar la conservación del mismo, si bien éste resulta difícil de alcanzar si se plantea un modelo turístico obsoleto (Royo, 2019, p. 382). Por eso, uno de los puntos más negativos ha sido el abandono y desuso de los mismos, de manera prolongada, lo que ha derivado en situaciones complicadas. Asimismo se debe considerar que, actualmente, la tecnología permite recuperar edificios en estados deficientes, aunque esto suponga un aumento del presupuesto para su recuperación.

Son numerosas las intervenciones en las que la arquitectura principal, más señorial, prevalece sobre el resto de elementos que configuran el conjunto definitivo, a pesar de que actualmente no se debe plantear una prelación en los valores de los bienes culturales, ni de ninguna de sus partes. Una de las intervenciones más controvertidas es la del "fachadismo" en la que se destruye por completo el interior y se sustituye por una obra nueva. Esto conlleva a la pérdida del bien y en ningún caso es aceptable que, además, se promocione que en esos casos el edificio es histórico y que ha sido rehabilitado, tal y como se indica en alguna web oficial, contradiciendo el concepto de autenticidad del patrimonio. Actuaciones así van en contra de los documentos internacionales de protección, entre los que destacan la Carta de Venecia, artículos 6 y 7 (Comisión redactora, 1964); la Carta europea del patrimonio arquitectónico, principios 


\section{A. J. Santana Guzmán}

1, 3, 6 y 9 (Consejo de Ministros de Europa, 1975/09/26); la Declaración de Ámsterdam, consideraciones b, f, e i (Comisión redactora 1975/10/21-25) y la Convención para la salvaguarda del patrimonio arquitectónico de Europa, artículos 2, 4, 10 y 15 (Estados miembros del Consejo de Europa, 1985/10/03).

Es esencial reseñar que las intervenciones arqueológicas realizadas en las parcelas afectadas han sacado a la luz restos y datos que se desconocían. Al igual que ocurre con la conservación de la arquitectura, en este caso también tenemos dos ejemplos extremos donde han aparecido vestigios de valor incalculable, pero que, o bien se han puesto en valor y se han abierto al público, como en el Museo Picasso, o bien siguen sin ser visitables, como en el Museo Carmen Thyssen (Ferarry, 2017/10/18). Evidentemente esta situación podría solucionarse ampliando la partida presupuestaria para tal necesidad; teniendo en cuenta el coste que supone, por parte de la administración local, el mantenimiento de tantos centros culturales, quizás se debería poner el énfasis en la recuperación del patrimonio autóctono, que es extremadamente frágil, ofertándose además como un recurso único de su territorio.

El último punto a destacar en relación a este patrimonio arquitectónico es la amplia ausencia de publicaciones específicas sobre la historia de los inmuebles y su reconversión. Al igual que ocurre con los catálogos de las colecciones, cuidadosamente trabajados por las propias entidades gestoras, debería planificarse un volumen sobre cada uno de los continentes que las aloja. Estos textos sirven para poner en valor y difundir los conjuntos y su devenir, influyendo su ausencia en el desconocimiento de los mismos por parte de turistas y locales. Actualmente son muy pocas las referencias existentes, destacando de entre todas los monográficos que el Museo Picasso Málaga ha dedicado tanto a su edificio como a los restos arqueológicos que acoge en sus sótanos (Giménez, 2004; Ladiano-Romero, 2006). El resto de referencias se pueden localizar en artículos científicos y de investigación, pero éstos no están al alcance directo del visitante que accede al museo, en su tienda y/o librería, tal como debiera ser. Es importante informar a la ciudadanía sobre los valores de su patrimonio para permitir su participación en los debates sobre el mismo (Santana, 2020-2021, p. 120).

\section{Referencias}

Ayuntamiento de Málaga. (s. f.). Mupam Museo del Patrimonio Municipal. Recuperado de https://museodelpatrimoniomunicipal.malaga.eu/portal/seccion 0016

Camacho Martínez, R. (2013). La recuperación de un edificio mudéjar de Málaga: de casa-palacio de Villalón a museo Carmen Thyssen. En M. I. Alvaro Zamora, C. Lomba Serrano, y J. L. Pano Gracia (Coord.), Estudios de Historia del Arte. Libro homenaje a Gonzalo M. Borrás Gualis (pp. 235-248). Zaragoza: Institución Fernando el Católico, Excma. Diputación. Recuperado de https://ifc.dpz.es/recursos/publicaciones/32/98/16camachomartinezpdf.pdf

Colección del Museo Ruso. (2015, 3 de marzo). Primeros días de apertura de la colección del Museo Ruso, San Petersburgo / Málaga. EnColección del Museo Ruso. Recuperado de https://www.coleccionmuseoruso.es/noticias/primeros-dias-apertura-lacoleccion-del-museo-ruso-san-petersburgo-malaga/

Colección del Vidrio y del Cristal de Málaga. (s. f.). Colección del Vidrio y Cristal de Málaga. Recuperado de https://museovidrioycristalmalaga.com/proximo-evento.html

Coloma Martín, I., García Gómez, F., Méndez Baiges, M. T., y Santana Guzmán, A. J. (2003). La ambigüedad de la memoria: bases para la reconstrucción del color del Mercado de Mayoristas de Málaga. Boletín de Arte, 24, 583-600. https://doi.org/10.24310/BoLArte.2003.v0i24.4701

Comisión redactora. (1964). Carta Internacional para la Conservación y Restauración de Monumentos / Carta de Venecia. M. J. Martínez Justicia (Trad.). Recuperado de https://ipce.mecd.gob.es/dam/jcr:b55d37b1-0009-4fec-b46f-364cfdd78b9d/1964-cartavenecia.pdf

Comisión redactora. (1975, 21 al 25 de octubre). Declaración de Ámsterdam. Recuperado de https://ipce.culturaydeporte.gob.es/dam/jcr:3105dc7a-8c2e-409d-94b5-b731fc21a8e2/1975-declaracion-amsterdam.pdf

Consejo de Ministros de Europa. (1975, 26 de septiembre). Carta europea del Patrimonio Arquitectónico. M. J. Martínez Justicia (Trad.). Recuperado de https://icomos.es/wp-content/uploads/2020/01/17.carta-europea-patrimonio.pdf 
Estados miembros del Consejo de Europa. (1985, 10 de marzo). Convención para la salvaguardia del patrimonio arquitectónico de Europa. M. J. Martínez Justicia (Trad.). Recuperado de https://ipce.culturaydeporte.gob.es/dam/jcr:73f8d55e-17db-4676-9d80962fb58eb3b7/1985-convencion-granada.pdf

Ferrary, M. (2017, 18 de ctubre). Aprueban hacer visitables los restos arqueológicos bajo el Museo Thyssen. En La Opinión de Málaga. Recuperado de https:/www.laopiniondemalaga.es/malaga/2017/10/16/aprueban-visitables-restos-arqueologicos$\underline{\text { museo/962281.html }}$

Fundación Picasso. (s. f.). Museo Casa Natal de Picasso. En Fundación Picasso Museo Casa Natal. Recuperado de https://fundacionpicasso.malaga.eu/portal/menu/seccion_0001/secciones/subSeccion 0002d/subSeccion 0001

García González, J. (2016). Arquitectura contemporánea y Arqueología: intervenciones en el Patrimonio (1985-2010). Tesis doctoral. Granada: Universidad de Granada. Recuperado de https://digibug.ugr.es/handle/10481/43879

Giménez, C. (Ed.). (2004). Arquitectura del Museo Picasso Málaga. Desde el siglo VI a. C. hasta el siglo XXI. Madrid: Museo Picasso Málaga (Fundación Museo Picasso de Málaga y Fundación Paul, Christine y Bernard Picasso).

Heredia Flores, V. M. (2010). La posada de San Felipe, sede del Museo del Vidrio y del Cristal de Málaga. En Isla de Arriarán Revista Cultural y Científica, XXXV (pp. 21-81). Recuperado de https://dialnet.unirioja.es/servlet/articulo?codigo=4298475

La Térmica. (s. f.). Edificio. En La Térmica. Recuperado de https://www.latermicamalaga.com/edificio/

Ladiano-Romero, B. (Dir.). (2006). Memoria arqueológica del Museo Picasso Málaga: desde los orígenes hasta el siglo V d. C. Málaga: Museo Picasso Málaga (Fundación Museo Picasso de Málaga y Fundación Paul, Christine y Bernard Picasso).

López, A. J. (2019, 5 de octubre). El Museo de Málaga tendrá que cambiar toda su climatización. En Sur. Recuperado de https://www.diariosur.es/culturas/museo-malaga-cambiar-20190509193009-nt.html

Martínez Madrid, R. (2013). La Asociación Amigos del Museo de Málaga, Bellas Artes y Arqueológico. Boletín de la Sociedad de Amigos de la Cultura de Vélez-Málaga, 12, 39-42. Recuperado de https://dialnet.unirioja.es/servlet/articulo?codigo=4284340

MUACPMÁLAGA. (s. f.). Museo Unicaja de Artes y Costumbres Populares. Recuperado de http://www.museoartespopulares.com/

Museo Carmen Thyssen Málaga. (s. f.). Vestigios arqueológicos en el subsuelo del Museo Carmen Thyssen. En Museo Carmen Thyssen Málaga. Recuperado de https://www.carmenthyssenmalaga.org/patrimonio-historico/restos-arqueologicos

Museo Picasso Málaga. (s. f.). El edificio. Museo Picasso Málaga. Recuperado de https://www.museopicassomalaga.org/arquitectura

Peláez, E. (2020, 3 de septiembre). Un incendio fortuito daña el artesonado y el techo de una sala del futuro Museo Picasso de Málaga. En El País. Recuperado de https://elpais.com/diario/2002/03/09/andalucia/1015629723 850215.html

Piedrola Lluch, M. A. (Dir.). (2016). Historia de un museo. Málaga: Ayuntamiento, Área de Cultura.

Romero Torres, J. L. (1989). Museo de Bellas Artes de Málaga. León: Everest.

Royo Naranjo, L. (2019). Conflictos y derivaciones de un proceso de "turistización" en el centro histórico de Málaga. Revista PH, 98, 282-285. http://doi.org/10.33349/2019.98.3612

Santana Guzmán, A. J. (2022-2021). Experiencias sobre el acercamiento del patrimonio malagueño a la ciudadanía. En Universitas Revista de Ciencias Sociales y Humanas, 33, 103-124. https://doi.org/10.17163/uni.n33.2020.05

Silva Pérez, R. y Fernández Salinas, V. (2017). El patrimonio en la reivindicación de Málaga. Agentes, instrumentos y estrategias. Investigaciones Geográficas, 67, 81-100. https://doi.org/10.14198/INGEO2017.67.05

Sur (2010, 17 de septiembre). El Museo Automovilístico arranca. En Sur. Recuperado de https://www.diariosur.es/v/20100917/cultura/museo-automovilistico-arranca-20100917.html

Vázquez, A. (2020, 16 de enero). La Térmica se despide de $500 \mathrm{~m} 2$ de historia. En La Opinión de Málaga. Recuperado de https://www.laopiniondemalaga.es/malaga/2020/01/16/termica-despide-500-m2-historia/1139031.html 